\title{
Adaptação do feijoeiro comum (Phaseolus vulgaris L.) à seca ${ }^{1}$
}

\author{
Cleber M. Guimarães ${ }^{2}$, Luís F. Stone ${ }^{2} \&$ Orivaldo Brunini ${ }^{3}$
}

\begin{abstract}
RESUMO
Realizou-se este trabalho tendo em vista o propósito de se estudar a adaptação de genótipos de feijoeiro comum (Phaseolus vulgaris L.) à seca, como suporte a programas de melhoramento que visem à criação de cultivares para regiões sujeitas a deficiência hídrica, mediante a avaliação do potencial da água nas folhas e da resistência difusiva estomática. Adicionalmente avaliou-se a técnica de medição da temperatura do dossel pela termometria de infravermelho para inferir o estado hídrico da planta. Os genótipos Carioca e RAB 96 foram submetidos, dos 20 dias após a emergência até a colheita, a dois tratamentos hídricos: irrigação adequada e com deficiência hídrica. Em geral, a cultivar Carioca manteve potenciais de água na folha mais altos e também melhor capacidade de recuperação hídrica, além de apresentar resistência difusiva estomática e temperatura do dossel mais baixas que a linhagem RAB 96 sendo, portanto, melhor adaptada à seca. A temperatura do dossel correlacionou-se significativamente com o potencial da água nas folhas e, devido a sua medição ser rápida e não-destrutiva, mostrou tratar-se de uma técnica útil no processo de seleção de genótipos para regiões sujeitas a deficiência hídrica.
\end{abstract}

Palavras-chave: potencial da água na folha, resistência difusiva estomática, temperatura do dossel, termômetro de infravermelho

\section{Common bean (Phaseolus vulgaris L.) adaptation to drought}

\begin{abstract}
The objective of this study was to investigate the common bean adaptation to drought, as support to breeding programs directed to regions with water deficiency, through the evaluation of leaf water potential and stomatal diffusive resistance. Furthermore, the canopy temperature was evaluated with the infrared thermometer technique to infer the plant water content. From twenty days after emergence until harvest, the genotypes Carioca and RAB 96 were submitted to two water treatments: adequate irrigation and water deficit. The 'Carioca' showed higher leaf water potentials and better water recovery capacity compared with 'RAB 96'. This cultivar also showed lower stomatal diffusive resistance and canopy temperature, due to its better adaptation to drought compared with 'RAB 96 '. The canopy temperature was significantly correlated to leaf water potential and since its measurement is rapid and non-destructive, hence, it is a useful technique for genotype selection to drought tolerance.
\end{abstract}

Key words: leaf water potential, stomatal diffusive resistance, canopy temperature, infrared thermometer

1 Parte da Tese de Doutorado apresentada pelo primeiro autor à UNICAMP

2 EMBRAPA Arroz e Feijão. CP 179, CEP 75375-000, Santo Antônio de Goiás, GO. Fone: (62) 3533-2178. E-mail: cleber@cnpaf.embrapa.br (Foto); $3533-2186$. stone@cnpaf.embrapa.br

${ }^{3}$ Instituto Agronômico de Campinas (IAC)/Seção de Climatologia. CP 28, CEP 13001-970, Campinas, SP. Fone (19) 3241-5188. E-mail: brunini@iac.sp.gov.br 


\section{INTRODUÇÃO}

No Brasil, o feijoeiro comum (Phaseolus vulgaris L.) é cultivado em praticamente todo o território nacional, em várias épocas de plantio, o que condiciona uma diversidade de condições climáticas. Aliados aos diferentes níveis de tecnologia usados, esses fatores contribuem para a baixa produtividade média nacional e instabilidade da produção. Entre os fatores climáticos, a deficiência hídrica é o mais importante. Singh (1995) relatou que, na América Latina, em cerca de $93 \%$ da área de cultivo de feijoeiro a necessidade hídrica da planta, durante o seu ciclo, não é satisfeita. Assim, é importante que as cultivares desenvolvidas para as condições de sequeiro apresentem adaptação ao estresse hídrico. A adaptação à deficiência hídrica, dentre outros fatores, decorre da manutenção de boa condição hídrica nos tecidos das plantas (Kramer \& Boyer, 1995), avaliada pelo potencial da água na planta, pela resistência difusiva estomática e pela temperatura do dossel (Bascur et al., 1985; Hsiao, 1990; Pimentel \& Perez, 2000). Vieira et al. (1991) verificaram que uma cultivar de arroz tolerante à seca apresentou, quando submetida a estresse hídrico, maiores potenciais de água da folha e menores valores de resistência difusiva estomática em relação à suscetível. Para a cultura do feijoeiro, Guimarães \& Zimmermann (1985) observaram que os genótipos mais resistentes à seca apresentaram potenciais da água na folha mais altos e sistemas radiculares mais desenvolvidos no perfil do solo, de 20 a $60 \mathrm{~cm}$ de profundidade, em comparação com o suscetível. Corroborando com esta informação, CIAT (1985a, b) e White \& Sponchiado (1985) concluíram que os genótipos de feijoeiro mais tolerantes à deficiência hídrica mantiveram potenciais da água na folha mais altos e resistências estomáticas mais baixas, por apresentaram sistemas radiculares mais profundos que os dos mais suscetíveis. Por sua vez, Vieira et al. (1989) concluíram que a cultivar de feijoeiro Aeté 3 mostrou maior tolerância à seca, por deter maiores valores de resistência estomática à difusão de vapor de água, movimentos foliares de fotonastismos mais pronunciados, e diminuição de emissão e crescimento das folhas em preferência à perda foliar mostrada pela cultivar Aroana 80. Segundo Pimentel \& Perez (2000), o potencial da água na folha é um ótimo indicador do efeito do estresse hídrico no feijoeiro e, aliado à área foliar e à massa da matéria seca da parte aérea, pode discriminar genótipos mais tolerantes à seca.

A temperatura do dossel é função do balanço da energia foliar e é também tanto mais alta quanto menor a perda de energia. Esta perda se dá de diversas formas, dentre as quais a transpiração, que será tanto mais intensa quanto melhores as condições hídricas da planta. A termometria infravermelha pode, assim, inferir o estado hídrico da planta e discriminar genótipos fisiologicamente mais adaptados à seca (Bascur et al., 1985).

Com este trabalho, objetivou-se estudar a adaptação de genótipos de feijoeiro à seca, como suporte a programas de melhoramento que visem à criação de cultivares para regiões sujeitas à deficiência hídrica, mediante a avaliação do potencial da água nas folhas e da resistência difusiva estomática.
Adicionalmente, avaliou-se a técnica de medição da temperatura do dossel pela termometria de infravermelho, para inferir o estado hídrico da planta.

\section{MATERIAL E MÉTODOS}

O estudo foi conduzido no período da seca (maio-julho), na área experimental da Embrapa Arroz e Feijão, em Santo Antônio de Goiás, GO, de coordenadas geográficas $16^{\circ} 28^{\prime}$ de latitude sul, $49^{\circ} 17^{\prime}$ de longitude oeste e altitude de $823,77 \mathrm{~mm}$, em sua estação agroclimática, em Latossolo Vermelho distrófico, de textura argilosa (EMBRAPA, 1994).

A adubação, utilizada de acordo com a análise do solo, foi de $300 \mathrm{~kg} \mathrm{ha}^{-1}$ do formulado comercial 5-30-15, na semeadura, e $100 \mathrm{~kg} \mathrm{ha}^{-1}$ de sulfato de amônio, em cobertura, aplicados cerca de 15 dias após a emergência. Os tratos culturais foram os recomendados para a cultura do feijoeiro (Araújo et al., 1996).

Usaram-se dois genótipos com ciclo vegetativo semelhante: Carioca e RAB 96; o primeiro é uma cultivar classificada como promissora para as condições de deficiência hídrica, pois apresenta bom grau de resistência à seca, avaliada pela produtividade de grãos em condições de deficiência hídrica e responde bem à irrigação (Guimarães \& Zimmermann, 1985), enquanto o segundo é uma linhagem mais produtiva em condições favoráveis de cultivo (Araújo, 1991).

Os genótipos foram mantidos sob boas condições hídricas até 20 dias após a emergência, quando a irrigação convencional foi substituída por uma linha central de aspersores, segundo metodologia utilizada por Hanks et al. (1976), que foi mantida até o fim do ciclo da cultura. Usou-se este sistema de irrigação com o objetivo de se induzir um gradiente de disponibilidade hídrica às plantas.

$\mathrm{O}$ experimento foi instalado próximo a uma barreira natural, para reduzir os efeitos do vento sobre as irrigações, que eram feitas ao anoitecer, durante períodos com menor intensidade de vento. A pressão da água na entrada da linha central de aspersores foi mantida a 0,25 $\mathrm{MPa}$. As lâminas de irrigação aplicadas foram monitoradas através de pluviômetros instalados na área experimental e as leituras foram feitas na manhã seguinte à irrigação.

A linha central foi instalada ao longo de um espaço de $1,0 \mathrm{~m}$ de largura deixado no centro do experimento e os genótipos semeados transversalmente à linha central, em ambos os lados, no espaçamento de $0,5 \mathrm{~m}$, com 10-12 plantas por metro, perfazendo 15 fileiras de $10 \mathrm{~m}$ de comprimento $\left(75 \mathrm{~m}^{2}\right)$. O gradiente de umidade foi dividido em dois níveis compreendendo, cada um, 15 fileiras de $5 \mathrm{~m}$, perfazendo a área total de $37,5 \mathrm{~m}^{2}$. O tratamento mais próximo da linha central recebeu suprimento adequado de água, $334 \mathrm{~mm}$, mantendo-se ao longo do ciclo potenciais da água do solo superiores a $-0,035 \mathrm{MPa}$, a $15 \mathrm{~cm}$ de profundidade, conforme recomendação de Silveira \& Stone (1994). O tratamento com deficiência hídrica recebeu $188,5 \mathrm{~mm}$, dos quais $75 \mathrm{~mm}$ foram aplicados antes da implantação dos tratamentos hídricos. Os tratamentos foram repetidos quatro vezes. Verificaram-se 23,9 mm de precipitação no período de condução do 
experimento, dos quais $23,3 \mathrm{~mm}$ ocorreram antes da aplicação dos tratamentos hídricos.

O estado hídrico das plantas foi monitorado por meio de medições do potencial da água na folha, da resistência difusiva estomática e da temperatura do dossel, realizadas durante o estádio da floração, aos 41, 43, 46, 48 e 50 dias após a emergência. As leituras do potencial da água na folha e da temperatura do dossel foram feitas das 7 às $18 \mathrm{~h}$, excetuando-se o período compreendido entre 11 e $12 \mathrm{~h}$. Com vistas à não interferência do orvalho formado na superfície das folhas sobre as leituras da resistência difusiva estomática, iniciaram-se essas medições às $9 \mathrm{~h}$, quando as folhas estavam secas.

A resistência difusiva estomática foi medida nas superfícies superior e inferior dos folíolos apicais, completamente desenvolvidos e com boa exposição solar. Usou-se uma metade da face do folíolo para determinação da leitura superior e a outra metade para a leitura inferior, adotando-se os cuidados de rotina preconizados para o manuseio do porômetro, LI-COR, modelo LI 1600, como a calibragem do equipamento antes do início das leituras. Estas foram expressas pela média de duas amostras.

O potencial da água na folha foi determinado com câmaras de pressão, Soil Moisture Equipment, modelo 3005. Usaram-se duas câmaras de pressão, operando simultaneamente; Essas leituras foram determinadas também em folíolos apicais completamente desenvolvidos. O valor do potencial da água reportado foi a média de duas leituras individuais, uma em cada câmara. A operação foi realizada conforme proposto por Scholander et al. (1965). O equipamento foi instalado no centro do experimento, para reduzir ao máximo o tempo entre a coleta da amostra e a operação de leitura.

Avaliou-se a temperatura do dossel através de um termômetro de infravermelho, marca AGA Thermopoint 80, que opera numa faixa de temperatura entre 30 e $1.370^{\circ} \mathrm{C}$ e é equipado com filtro espectral, que reduz a interferência ocasionada pela radiação solar, pela variação da coloração dos substratos e pelo vapor da água na atmosfera. Usando-se o filtro, aumenta-se a precisão do instrumento e se reduz o erro ocasionado pela distância ao objeto focado.

A radiação fotossinteticamente ativa, em $\mu \mathrm{E} \mathrm{m} \mathrm{m}^{-2} \mathrm{~s}^{-1}$, foi medida com o auxílio de um monitor solar marca LI-COR, modelo LI 1776, e um sensor marca LI-COR, modelo LI 191SB Line Quantum, monitorada das 7 às $18 \mathrm{~h}$.

\section{RESULTADOS E DISCUSSÃO}

Os potenciais da água na folha $\left(\Psi_{\mathrm{f}}\right)$ observados nas primeiras horas da manhã, foram semelhantes entre os genótipos, tanto no tratamento sob deficiência hídrica como no irrigado adequadamente (Figuras 1A e 1B); observou-se, também, que variaram ao longo do dia e segundo modelos matemáticos quadráticos, devido à variação diurna da demanda atmosférica por água, inferida pela radiação fotossinteticamente ativa, isenta de cobertura solar, em $\mu \mathrm{E} \mathrm{s}^{-1} \mathrm{~m}^{-2}$, que foi descrita pela equação $Y=-64,855 x^{2}+1605,796 x-8318,84$
$\left(\mathrm{R}^{2}=0,94^{* *}\right)$, com ponto de máxima intensidade de radiação às 12:23 h. $\mathrm{O} \Psi_{\mathrm{f}}$ mínimo da 'Carioca' (-0,97 MPa), quando submetido a deficiência hídrica, foi observado às 13:00 h, enquanto o mínimo da 'RAB 96' (-1,07 $\mathrm{MPa})$ foi verificado às 13:08 h (Figura 1A). O comportamento hídrico dos dois genótipos foi semelhante quando irrigados adequadamente, pois apresentaram $\Psi_{\mathrm{f}}$ semelhante durante todo o dia, com mínimos próximos de $-0,88 \mathrm{MPa}$ às 12:59 h (Figura 1B).

A deficiência hídrica nas plantas é tanto maior quanto menor o suprimento de água pelas raízes. Como a 'RAB 96', quando submetida ao tratamento com deficiência hídrica, apresentou potencial mínimo menor, conclui-se que fatores ligados à absorção de água determinaram maior redução do $\Psi_{\mathrm{f}}$ em relação à 'Carioca'. Guimarães et al. (1996) constataram que a eficiência radicular na absorção de água foi mais elevada na 'Carioca' que na 'RAB 96', da superfície aos $120 \mathrm{~cm}$ de profundidade; a diferença entre elas foi maior nas camadas mais profundas, em que a 'Carioca' também apresentou maior quantidade relativa do sistema radicular. Boyer et al. (1980) e Vieira et al. (1991) também observaram variabilidade intraespecífica do potencial da água durante as horas com alta radiação solar, a qual foi atribuída à sensibilidade estomática ou à profundidade diferenciada do sistema radicular.

A intensidade da recuperação do potencial da água na folha nos dois genótipos foi semelhante no tratamento irrigado adequadamente, porém diferiu no tratamento com deficiência hídrica. Às 18:00 h, quando terminaram as avaliações, a 'Carioca' e a 'RAB 96' apresentaram valores de $\Psi_{\mathrm{f}}$ de $-0,3 \mathrm{MPa}$ no tratamento irrigado porém, no tratamento com deficiência hídrica, os valores foram de $-0,37$ e -0,48 MPa, na 'Carioca' e 'RAB 96', respectivamente o que pode ser explicado, como já discutido, pela diferença entre os genótipos quanto à eficiência na absorção de água e à densidade e profundidade do sistema radicular (Guimarães et al., 1996). Esta afirmativa concorda com Ekanayake et al. (1985), os quais relataram que a capacidade de recuperação à deficiência hídrica se correlacionou com o comprimento radicular, número de raízes finas e volume radicular total. Pimentel \& Perez (2000) também verificaram que a cultivar Carioca apresentou rápida recuperação do potencial de água da folha.

As pequenas diferenças dos $\Psi_{\mathrm{f}}$ entre os tratamentos hídricos são explicadas pelo sistema de deficiência hídrica aplicado. Por ter sido induzido na fase inicial do ciclo da cultura, permitiu que a planta se adaptasse, ou seja, que mecanismos de tolerância à seca fossem acionados, como o ajustamento do sistema radicular e da área foliar, o que dificilmente acontece quando ocorrem deficiência hídricas repentinas.

As Figuras 1C e 1D ilustram a variação do comportamento estomático das faces superior e inferior dos folíolos, respectivamente, avaliado pela resistência difusiva estomática $\left(\mathrm{R}_{\mathrm{f}}\right)$ ao longo do dia, sob condições de deficiência hídrica. Os valores de $R_{f}$ durante o período da manhã foram semelhantes entre os genótipos, em ambas as faces dos folíolos; observou-se, ainda, que variaram ao longo do dia, segundo modelos matemáticos quadráticos, com mínimos próximos 

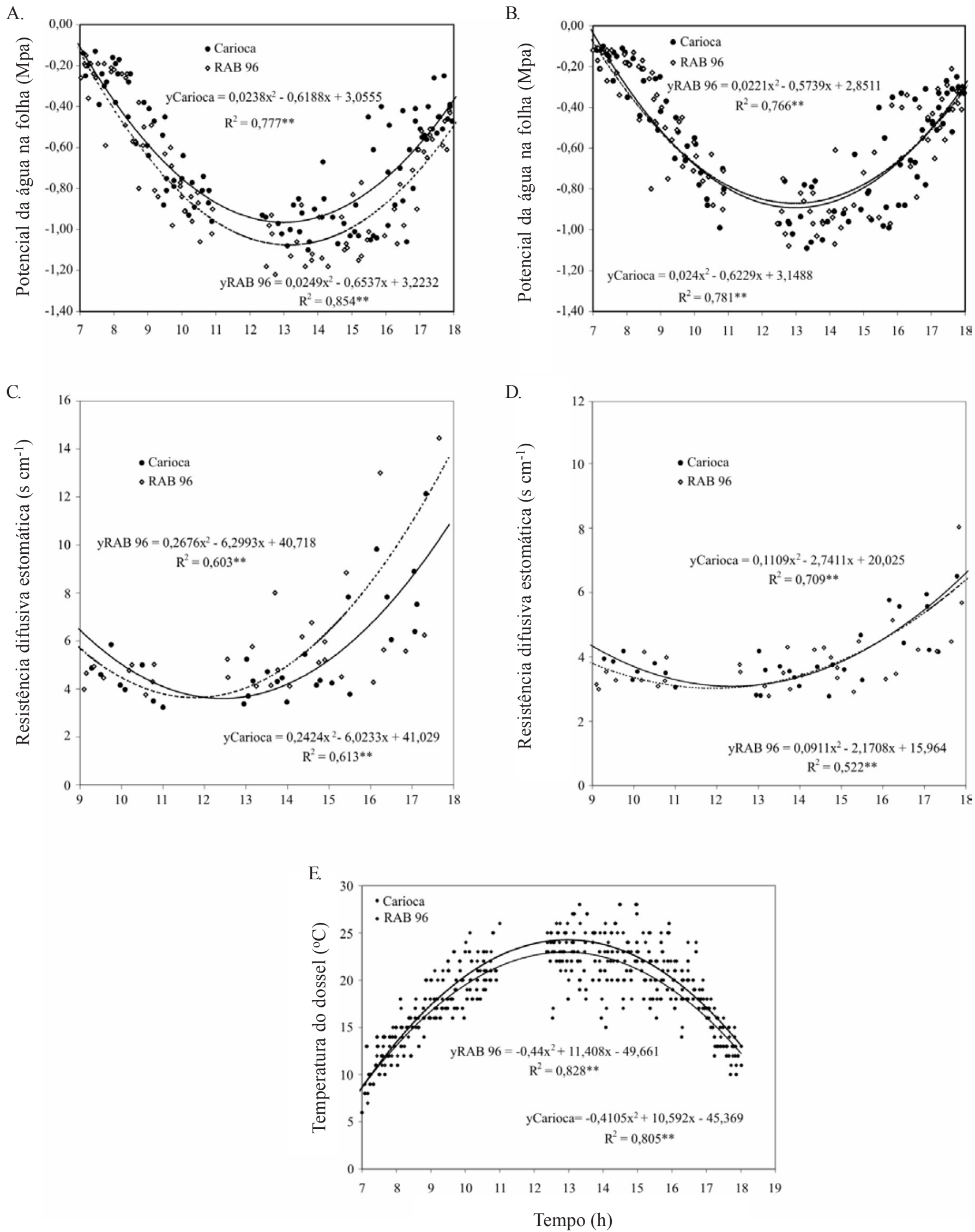

Figura 1. Variação diurna do potencial da água na folha sob deficiência hídrica (A) e irrigação adequada (B), da resistência difusiva estomática da face superior (C) e inferior (D) dos folíolos, e da temperatura do dossel (E) dos genótipos Carioca e RAB 96, medida aos 41, 43, 46, 48 e 50 dias após a emergência. 
de 3,63 s cm $\mathrm{s}^{-1}$, entre 12:25 e 12:46 h. Durante o período da tarde a cultivar Carioca manteve valores menores comparativamente aos observados na 'RAB 96'. A diferença entre elas se manteve crescente até o fim do período diurno, às $18: 00 \mathrm{~h}$, quando se registraram resistências difusivas de $11,1 \mathrm{e}$ $14,0 \mathrm{~s} \mathrm{~cm}^{-1}$ na 'Carioca' e 'RAB 96', respectivamente.

O comportamento estomático dos genótipos é uma resposta ao estado hídrico das plantas. A cultivar Carioca apresentou menor $\mathrm{R}_{\mathrm{f}}$ em função do seu melhor estado hídrico, devido à sua melhor capacidade de reposição da água transpirada, conforme discutido anteriormente.

A face inferior também apresentou variação diurna da resistência estomática descrita por modelos matemáticos de segundo grau. Os valores mínimos foram observados entre 11:55 e 12:22 h; entretanto, os valores da resistência difusiva da face inferior dos folíolos desses genótipos não diferiram entre si durante o dia e foram mais baixos, comparativamente aos observados na face superior, por não receberem a incidência direta da radiação solar (Figura 1D).

Os dados indicam que a 'Carioca' manteve maior taxa de transpiração durante o período do dia com maior demanda evaporativa da atmosfera que a 'RAB 96' e, mesmo assim, apresentou maior capacidade de recuperação do seu potencial da água na folha após o início da redução da radiação solar, por apresentar melhor distribuição e eficiência do seu sistema radicular (Guimarães et al., 1996). White \& Sponchiado (1985) também verificaram que os genótipos de feijoeiro mais resistentes à seca mantiveram menores valores de resistência difusiva durante períodos de deficiência hídrica, devido ao sistema radicular mais profundo.

Constatou-se que ambos os genótipos responderam termicamente ao aumento da radiação solar e que a sensibilidade das plantas a este fator diferiu entre eles, quando submetidos a deficiência hídrica (Figura 1E). Tanto no tratamento irrigado adequadamente como no com deficiência hídrica, a temperatura do dossel $\left(\mathrm{T}_{\mathrm{d}}\right)$ aumentou ao longo do dia, segundo modelos matemáticos quadráticos. As plantas irrigadas de forma adequada apresentaram menor aumento da temperatura do dossel devido à maior perda de energia térmica ocorrida com a também maior transpiração, condições em que a $T_{d}$ da 'Carioca' e da 'RAB 96' variou de forma semelhante ao longo do dia, segundo os modelos matemáticos $\mathrm{y}=-0,4069 \mathrm{x}^{2}+10,496 \mathrm{x}-44,904$ $\left(\mathrm{R}^{2}=0,79 * *\right)$ e $\mathrm{y}=-0,402 \mathrm{x}^{2}+10,372 \mathrm{x}-44,088$ $\left(\mathrm{R}^{2}=0,79^{* *}\right)$, respectivamente, registrando-se máximo de $22,8{ }^{\circ} \mathrm{C}$ às $12: 54 \mathrm{~h}$; entretanto, quando submetidas a deficiência hídrica, transpiraram menos e, conseqüentemente, tiveram sua temperatura aumentada de maneira intensa. Nestas condições hídricas, a cultivar Carioca, por ter apresentado menor resistência estomática que a 'RAB 96' e, em conseqüência, maior transpiração e maior perda de energia térmica, apresentou menores $T_{\mathrm{d}}$. A máxima da 'Carioca' $\left(23,0^{\circ} \mathrm{C}\right)$ foi observada às $12: 54 \mathrm{~h}$, enquanto a máxima da 'RAB $96^{\prime}$ ' $\left(24,3{ }^{\circ} \mathrm{C}\right)$ foi constatada às 12:56 h (Figura 1E).

O coeficiente de correlação da temperatura do dossel com o estado hídrico das plantas, medido pelo potencial da água nas folhas, foi de $-0,8280(\mathrm{p}<0,0001)$ sugerindo que a ter- mometria de infravermelho é eficiente na inferência do estado hídrico da planta e, portanto, útil para discriminar genótipos em programas de resistência à seca, pois é também um método de manuseio rápido, simples e não destrutivo de plantas. Pazzetti et al. (1993) notaram que plantas de feijoeiro submetidas a estresse hídrico apresentavam maiores temperaturas do dossel em relação às não-estressadas e, ainda, que a temperatura do dossel mostrou relacionamento estreito com os componentes da produção e a produtividade.

\section{CONCLUSÕES}

1. Sob condições de deficiência hídrica, a cultivar Carioca apresenta maior capacidade de recuperação e manutenção de altos potenciais de água na folha que a linhagem RAB 96.

2. A cultivar Carioca apresenta, também, sob deficiência hídrica, resistência difusiva estomática e temperatura do dossel menores que a linhagem RAB 96.

3. A termometria de infravermelho é uma técnica útil no processo de seleção de genótipos para as regiões sujeitas a deficiência hídrica.

\section{LITERATURA CITADA}

Araújo, G. A. de. A. Avaliação de cultivares de feijão a diferentes regiões do Estado de Minas Gerais. Viçosa: EPAMIG, 1991. 13p. Relatório

Araujo, R. S.; Rava, C. A.; Stone, L.F.; Zimmermann. M. J. de O. (coords). Cultura do feijoeiro comum no Brasil. Piracicaba: Associação Brasileira para Pesquisa de Potassa e do Fosfato, 1996. 786p.

Bascur, G.; Oliva, M. A.; Laing, D. Termometria infrarroja en selección de genotipos de frijol (Phaseolus vulgaris L.) resistentes a la sequía. I. Bases fisiológicas. Turrialba, San José, v.35, n.1, p.43-47, 1985.

Boyer, J. S.; Johnson, R. R.; Saupe, S. G. Afternoon water deficits and grain yields in old and new soybean cultivars. Agronomy Journal, Madison, v.72, n.6, p.981-986, 1980.

CIAT, Colombia. Bean program: Annual report 1984. Cali: CIAT. 1985a. p.92-96. Working Document, 7

CIAT, Colombia. CIAT Report 1985. Cali: CIAT 1985b. p.14-15.

Ekanayake, I. J.; O’toole, J. C.; Garrity, D. P.; Masajo, T. M. Inheritance of root characters and their relations to drought resistance in rice. Crop Science, Madison, v.25, n.6, p.927933, 1985.

EMBRAPA - Empresa Brasileira de Pesquisa Agropecuária. Centro Nacional de Pesquisa de Arroz e Feijão (Goiânia, GO). Relatório técnico 1990-1992. Goiânia, 1994. 325p. EMBRAPACNPAF. Documentos, 51

Guimarães, C. M.; Brunini, O.; Stone, L. F. Adaptação do feijoeiro (Phaseolus vulgaris L.) à seca. I. Densidade e eficiência radicular. Pesquisa Agropecuária Brasileira, Brasília, v.31, n.6, p.393-399, 1996. 
Guimarães, C. M.; Zimmermann, M. J. Deficiência hídrica em feijão. In: Reunion de Trabajo sobre Mejoramiento en Frijol en Brasil con Enfasis en Tolerancia a Sequia, 1985, Cali. Anais... Cali: CIAT, 1985. p.15-28.

Hanks, R. J.; Keller, J.; Rasmussen, V. P.; Wilson, G. D. Line source sprinkler for continuous variable irrigation-crop production studies. Soil Science Society of America Journal, Madison, v.40, n.3, p.426-429, 1976.

Hsiao, T. C. Measurements of plant water status. In: Stewart, B. A.; Nielsen, D. R. (Eds.). Irrigation of agricultural crops. New York: American Society of Agronomy, 1990. p.244-280.

Kramer, P. J.; Boyers, J. S. Evolution and agriculture. In: Kramer, P. J.; Boyers, J. S. (Eds.). Water relations of plants and soils. San Diego: Academic Press, 1995. p.377-404.

Pazzetti, G. A.; Oliva, M. A.; Lopes, N. F. Aplicação da termometria ao infravermelho à irrigação do feijoeiro: crescimento e produtividade. Pesquisa Agropecuária Brasileira, Brasília, v.28, n.12, p.1371-1377, 1993.

Pimentel, C.; Perez, A. J. de La. Estabelecimento de parâmetros para avaliação de tolerância à seca, em genótipos de feijoeiro. Pesquisa Agropecuária Brasileira, Brasília, v.35, n.1, p.31-39, 2000 .
Scholander, P. F.; Hammel, H. T.; Bradstreet, E. D.; Hemmingsen, E. A. Sap pressure in vascular plants. Science, Washington, v.148, n.3668, p.339-346, 1965.

Silveira, P. M. da; Stone, L. F. Manejo da irrigação do feijoeiro: uso do tensiômetro e avaliação do desempenho do pivô central. Brasília: EMBRAPA-SPI, 1994. 46p. EMBRAPA-CNPAF. Documentos, 27

Singh, S. P. Selection for water-stress tolerance in interracial populations of common bean. Crop Science, Madison, v.35, n.1, p.118-124, 1995.

Vieira, A. R. R.; Steinmetz, S.; Brunini, O. Resposta de duas cultivares de arroz a níveis de água no solo. Pesquisa Agropecuária Brasileira, Brasília, v.26, n.7, p.927-934, 1991.

Vieira, H. J.; Bergamaschi, H.; Angelocci, L. R.; Libardi, P. L. Comportamento de duas variedades de feijoeiro sob dois regimes de disponibilidade hídrica no solo. II. Resistência estomática à difusão de vapor, densidade de fluxo transpiratório e potenciais da água na planta. Pesquisa Agropecuária Brasileira, Brasília, v.24, n.9, p.1045-1053, 1989.

White, J. W.; Sponchiado, B. N. Tolerancia del frijol a la sequía: interrogantes y algunas respuestas. Hojas de Frijol para América Latina, Cali, v.7, n.1, p.1-3, 7, 1985. 